\title{
SMOKERS' SELF-CATEGORIZATION AND THE REDUCTION OF COGNITIVE DISSONANCE
}

\author{
Renata Tagliacozzo \\ Mental Health Research Institute, University of Michigan
}

\begin{abstract}
Sixty per cent of a sample of smokers who smoked between one and two packages of cigarettes per day considered themselves "moderate" smokers, while the remaining $40 \%$ considered themselves "heavy" smokers. This study compares the answers of these two groups of smokers to questions concerning the health risk of smoking. The results suggest that those respondents who assigned themselves to the lower-risk category, i.e., the "moderate", were more aware of the pathological, long-term effects of smoking than the smokers who classified themselves as "heavy" smokers. The smokers' tendency to minimize the extent of their smoking, as well as the avoidance of words which have threatening association for the smoker were interpreted as a means for reducing cognitive dissonance.
\end{abstract}

When some persistent behavior on the part of an individual conflicts with his knowledge that the behavior is inappropriate or even dangerous, a state of cognitive dissonance is created (Festinger, 1957). One way of reducing the dissonance is to change the behavior itself. But the change may be difficult, or painful, or it may require a stronger effort than one is willing to exert. If the behavior cannot be changed, then perhaps the perception of the behavior can be altered in a way that reduces the dissonance.

One way of assessing how people perceive some particular aspect of their behavior is to ask them to assign themselves to one of a set of preestablished categories along some dimension of that behavior. In this study we investigated the smokers' self-categorization as related to their daily consumption of cigarettes. The data for this investigation are part of a survey that we carried out dealing with the smokers' avoidance of information which tends to increase their cognitive dissonance (Tagliacozzo, 1978). In the returns of a questionnaire distributed to 500 individuals attending classes at the Washtenaw Community College in Ann Arbor, Michigan, we found that 155 were regular smokers. Of these, $41 \%$ were male and $59 \%$ female. Their age ranged from 18 to 57 , with a median of $25 \mathrm{yr}$. Fifty-four per cent qualified themselves as students, while the remaining reported being engaged in a variety of occupations (technical, professional, clerical, trade, service).

The 155 smokers were asked whether they smoked (a) more than two packs per day; (b) between one and two packs; (c) between half and one pack; (d) 10 cigarettes or less. Five of them checked the first category, 60 the second, 66 the third, and 24 the fourth. Later in the questionnaire, the respondents were asked if they considered themselves to be "light", "moderate", or "heavy" smokers. The distribution of the smokers according to amount smoked and to self-categorization is shown in Table 1. Not included in the table are two respondents who checked the space in between "light" and "moderate".

The table shows that a very high percentage of the respondents who smoked 10 cigarettes or less $(86.4 \%)$ considered themselves "light" smokers, and a similarly high percentage of those smoking between half and one pack $(84.8 \%)$ called themselves "moderate" smokers. But only $40 \%$ of the respondents who smoked between one and two packs per day assigned themselves to the category of "heavy" smokers, while $60 \%$ classified themselves as "moderate".

Since no explicit norms are to be found, either in the scientific literature or in the information disseminated by health agencies and clinical organizations, defining the parameters of heavy, moderate, and light smoking, any dividing line between the categories is to some extent arbitrary. Nevertheless, if one wants to study smoking behavior, subjects must be grouped. In most surveys and experimental studies the dividing line 
Table 1. Daily consumption of cigarettes and smokers'self-categorization $(N=153)$

\begin{tabular}{|c|c|c|c|c|c|c|c|c|}
\hline \multirow[b]{3}{*}{ Self-categorization } & \multicolumn{8}{|c|}{ Daily consumption of cigarettes } \\
\hline & \multicolumn{2}{|c|}{$\begin{array}{l}10 \mathrm{cgts} \\
\text { or less }\end{array}$} & \multicolumn{2}{|c|}{$\begin{array}{l}1 / 2-1 \\
\text { pack }\end{array}$} & \multicolumn{2}{|c|}{$\begin{array}{c}1-2 \\
\text { packs }\end{array}$} & \multicolumn{2}{|c|}{$\begin{array}{c}\text { More than } \\
2 \text { packs }\end{array}$} \\
\hline & $\mathrm{N}$ & 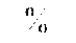 & $\mathbf{N}$ & $\%$ & N & $\because$ & $\mathrm{N}$ & $\%$ \\
\hline "Light" & 19 & 86.4 & 8 & 12.1 & & & & \\
\hline "Moderate" & 3 & 13.6 & 56 & 84.8 & 36 & 60.0 & & \\
\hline "Heavy" & & & 2 & 3.0 & 24 & 40.0 & 5 & 100.0 \\
\hline Total & 22 & & 66 & & 60 & & 5 & \\
\hline
\end{tabular}

between moderate and heavy smoking is placed either at 1 pack ( 20 cigarettes) or at 24 cigarettes per day. Whenever this is done, the explicit or implicit assumption is made that the smokers above that line are to be considered heavy smokers. This delimitation of "heavy" is supported by data suggesting that physiological addiction, as distinct from psycho-social determinants of smoking, plays an important role in maintaining the smoking behavior of people who smoke over 1 pack of cigarettes per day, but not in those who smoke less. Schachter showed that the tendency to keep constant the nicotine intake could be found in smokers who smoked more, but not in those who smoked less than 1 pack per day (Schachter, 1977). Russell, in his classification of types of smoking, points out the prevalence of addictive smoking in smokers who smoke more than 1 pack per day (Russell, 1974).

There is no assurance, of course, that the general public will make the same type of distinction between heavy and moderate smoking as researchers do, or that the same standards will be applied by all smokers to their self-categorization. Education, attitudes, and personal experiences may influence the smokers' response. The smoker, for instance, whose friend smokes three packs a day may perceive his own smoking of one and a half packs as moderate. But the significant amount of information passed to the general public through the mass media and through information materials at doctors' offices and hospitals suggests that some uniformity in judgement may be expected, and that the standards for the judgement will not differ substantially from those of researchers in the field. The prediction of the evil effects of smoking, for instance, found in much of the anti-smoking material distributed to the general public, frequently refers to the smoker "who smokes one pack or more per day", a reference which fosters the perception of the one-package level as the cut-off point between moderate and heavy smoking.

The finding that $60 \%$ of the 1-2 pack smokers categorized themselves as moderate smokers was therefore contrary to our expectations. This result could be explained, perhaps, by hypothesizing that the majority of the 60 smokers in that range were smoking very little over 1 pack per day. It would have been reasonable for such smokers to place themselves in the "moderate" category, as most of the 1-pack smokers did. To check this possibility, we estimated the distribution of smokers in the 1-2 pack range, using least square linear regression to fit the logarithm of the number of cigarettes (between 20 and 40 ) to the cumulative percentage of the population smoking that number of cigarettes or less. This indicates that $69.48 \%$ of the sample smoked up to 25 cigarettes. If from this percentage we substract $57.52 \%$ (the cumulative percentage of smokers who smoke 20 cigarettes or less), we find that $12 \%$ of the entire sample $(\mathrm{N}=153)$, or 18 smokers, are expected to fall in the 20-25 cigarettes interval. Smokers smoking between 20 and 22 cigarettes would be expected to be $6(4 \%$ of the sample).

The possibility that a large number of the 1-2 pack smokers identified themselves as "moderate" because they were very close to the lower end of the range does not seem therefore very plausible. Also to be considered is that the distribution of amount smoked is based on self-reporting. Smokers usually do a good deal of rounding off when they estimate their average daily consumption. It is very likely that in our sample many of the smokers who smoked 21 or 22 or 23 cigarettes per day placed themselves in the $\frac{1}{2}-1$ pack rather than in the 1-2 pack category. It follows, then, that those who placed 
themselves in the latter category were probably at sufficient distance from the 1-pack dividing line to insure little overlap with the lower consumption category.*

People often tend to minimize their problem behavior. This happens, for instance, in the case of problem drinkers, many of whom deny being heavy drinkers (Bowden, 1976). We wondered if the self-categorization of "moderate" in people who smoked between 1 and 2 packs a day may have resulted from social pressures and disapproval. In view of the fact that heavy smoking, while not as socially acceptable now as in the past, does not carry a social stigma as heavy drinking does, even this explanation does not seem tenable.

If we examine our data in the framework of the theory of cognitive dissonance, we find a more convincing explanation of our results. Since it is well known that the risk of lung cancer, heart diseases, and other pathological conditions increases proportionally to the amount of tobacco smoked (Doll, 1977; Wynder, 1977), considering oneself a moderate smoker may offer some partial reassurance that one's risk is not as great as that of other, heavier smokers. In other words, by placing themselves in a lower-risk category, the smokers are trying to reduce their cognitive dissonance. Earlier studies by Feather suggested an analogous interpretation to explain some differences between smokers and non-smokers in evaluating information on the risk of lung cancer (Feather, 1963). The high estimate given by smokers of the number of cigarettes which is "truly dangerous" was also interpreted as a way smokers place themselves in a lower-risk category (Pervin \& Yatko, 1965). On the other hand, Eiser's interpretation of the self-attribution of addiction as a "means of dissonance resolution" would seem-if we equate his sample of smokers who considered themselves "addicted to cigarettes" with our smokers who qualified themselves as "heavy" smokers-to be in contradiction with our argument (Eiser et al., 1978).

To verify whether the smokers who considered themselves "moderate" and those who considered themselves "heavy" differed in some dimension related to their perception, beliefs, and attitudes concerning the risk of smoking, we made a detailed comparison of the responses of the two groups.

\section{COMPARISON OF "MODERATE" AND "HEAVY" SMOKERS}

In the following analysis only those smokers who reported smoking between one and two packages of cigarettes per day were considered $(\mathrm{N}=60)$. The terms "heavy" and "moderate", when set off by quotation marks, indicate the self-categorization of the smokers.

Of the 58 respondents who identified their sex ( $25 \mathrm{M}$ and $33 \mathrm{~F}) 76.0 \%$ of the males as opposed to $45.5 \%$ of the females considered themselves "moderate". The difference is significant at the 0.05 level of confidence $\left(\chi^{2}=4.287\right.$; d.f. $\left.=1 ; P<0.05\right)$. The "moderate" response prevailed in the age range from 23 to 37 , while in both the younger and the older groups the "heavy" response was the preferred one. The ratio of "moderate" to "heavy" responses also increased with the number of years from initiation of smoking behavior, but went down again after $20 \mathrm{yr}$ of smoking.

With the exception of one respondent who did not believe that smoking was bad for her because she did not inhale, one who "did not know", and one who did not answer, all smokers in the 1-2-pack category believed that smoking was bad for their health. The percentage of smokers who wished to stop smoking was not substantially different in the "moderate" and "heavy" response groups $(58.3$ vs $62.5 \%)$. Fifty-four point five percent of the "moderate" and $46.6 \%$ of the "heavy" respondents who wished to stop smoking answered affirmatively to the question of whether they would go to a free clinic to help them to stop smoking. A somewhat higher percentage of respondents

\footnotetext{
*Some authors indicate that the "... mean rates of reported tobacco use do not coincide with midpoints of class intervals but usually lie between the 80 th and 95 th percentile of the interval". (Gori G. B. Letter in Science, 1979, 204, No. 4394, 691.)
} 
in the "moderate" group as compared to the "heavy" group had tried to quit in the past $(71.4$ vs $62.5 \%$ ). All the above differences were not statistically significant.

The majority of the respondents in the entire sample believed that smoking is a health risk for all smokers. Only seven respondents in the 1-2-pack category gave the atypical response that smoking is a health risk for heavy smokers only. It is interesting that five of the seven responses were in the "moderate" group. This reinforces the impression that the smokers of this group tend to remove themselves from the population at risk. But the number of cases is too small to consider this result other than suggestive.

From the data it appears therefore that in their answers to "yes-no" questions concerning their attitudes and beliefs on the risk of smoking the 1-2-pack smokers who call themselves "moderate" do not differ substantially from those who consider themselves "heavy" smokers. The following analysis of the answers to one of the open-ended questions, however, gave some indication that the two groups' perception of the personal risk of smoking may be different.

\section{CONTENT ANALYSIS OF ANSWERS ON THE EFFECTS OF SMOKING}

The smokers who had admitted believing that smoking was bad for their health (35 in the "moderate" and 22 in the "heavy" self-categorization groups) were asked in which way (they believed that smoking was bad for their health). Six in the first group (Group A: "Moderate") and four in the second (Group B: "Heavy") did not answer the question, leaving 29 and 18 answers respectively to be analyzed. Two types of answers emerged at a first inspection, one characterized by the description of particular symptoms or pathological conditions (e.g., "shortness of breath", "lung cancer"), or simply by the naming of the affected organs or functions (e.g., "lungs", "heart"). These answers could be called specific. Other answers, that we called generic, were vague and all-inclusive (e.g., "every way", "general health"). The generic answers were slightly more frequent in Group B than in Group A, but the difference is small and statistically not significant (see Table 2).

More marked differences are found when one compares the two sets of specific answers. In Group B a high percentage of answers are confined to a single effect of smoking, while in Group A the more frequent type of response lists two or more different effects of smoking (see Table 3).

The question eliciting the answer that we are analyzing ("in which way"... do you believe smoking is bad for your health) was in some respect ambiguous, since it left to the responders the decision of whether they should consider the present or the future state of their health. Some respondents evidently chose to pay attention to the latter. There is no doubt that responses such as "cancer and heart disease", "destroys lungs", "shorter life" refer to the future, long-term effects of smoking. Also it seems clear that when answering "breathing short when walking fast", "makes me weak sometimes", the respondents are referring to the immediate, personal effects of smoking. But in other cases (e.g., "restriction to proper breathing", "loss of breath and energy") it is difficult to decide whether the respondents were reporting what they were actually experiencing, or were referring to problems that they were anticipating for a more or less distant future.

Table 2. Answers to the question: "In which way" (... do you believe smoking is bad for your health) by 1-2-pack smokers

\begin{tabular}{lrrrr}
\hline & \multicolumn{4}{c}{ Self-categorization } \\
\multicolumn{1}{l}{ Group $\mathrm{A}:$ :Moderate" } & Group B: "Heavy" \\
\hline Type of answer & $\mathrm{N}$ & $\%$ & $\mathrm{~N}$ & $\%$ \\
\hline 1. Generic or vague & 5 & 17.2 & 4 & 22.2 \\
2. Specific & 24 & 82.8 & 14 & 77.8 \\
\hline
\end{tabular}


Table 3. Number and type of reported ill effects of smoking by 1-2-pack smokers*

\begin{tabular}{|c|c|c|c|c|}
\hline \multirow[b]{3}{*}{ Effects of smoking on health } & \multicolumn{4}{|c|}{ Self-categorization } \\
\hline & \multicolumn{2}{|c|}{$\begin{array}{c}\text { Group A: "Moderate" } \\
(\mathrm{N}=24)\end{array}$} & \multicolumn{2}{|c|}{$\begin{array}{c}\text { Group B: "Heavy" } \\
(N=14)\end{array}$} \\
\hline & $\mathbf{N}$ & $\%$ & $\mathrm{~N}$ & $\%$ \\
\hline \multicolumn{5}{|l|}{ I. Number } \\
\hline (a) One & 9 & 37.5 & 10 & 71.4 \\
\hline (b) Two or more & 15 & 62.5 & 4 & 28.6 \\
\hline \multicolumn{5}{|l|}{ II. Type } \\
\hline (a) Pathological conditions & 12 & 50.0 & 6 & 42.9 \\
\hline (b) Symptom and disturbance & 7 & 29.2 & $?$ & 50.0 \\
\hline (c) Mixed & 5 & 20.8 & 1 & 7.1 \\
\hline
\end{tabular}

*Only specific answers (see Table 2) were included.

It occurred to us that another dichotomy could be used, which appeared to be strongly associated with the long-term/immediate-effect dichotomy, but had the advantage of being more easily identifiable. Most answers could be categorized as referring either to a pathological process affecting an organ or a system, or to a symptom or disturbance of normal functions. A few answers referred to both. Under this classification, "lung cancer" is a pathological process, but "restriction to proper breathing" is a symptom. When the answer consisted only of the name of an organ, or organs, without any specification (e.g., "lungs", "heart"), we assigned it to the "pathological condition" category. In this category we also included answers containing the word respiratory (e.g., "respiratory problem", "respiratory functions"), while we assigned to the "symptoms" category those containing the word breath or breathing.

Table 3 'shows a higher percentage of answers referring to symptoms among the respondents who identified themselves as heavy smokers, while answers concerning pathological conditions were more prevalent among respondents who considered themselves moderate smokers. Answers referring both to pathological conditions and symptoms (mixed) were also more frequent among the "moderate" smokers. The differences were not statistically significant.

In any discussion of the health risk of cigarette smoking, certain words or phrases which have threatening connotations for the smoker occur frequently. We compared the incidence of three such words-lungs, heart, and cancer - in the two sets of answers. We counted separately the number of answers in which each of these words occurred, alone or in combination. A large discrepancy in the frequency of the word lung in the answers of the "moderate" and "heavy" groups was evident. The word appeared in 13 of the answers of Group A and only 2 of the answers of Group B (see Table 4). The difference is statistically significant at the 0.05 level of confidence $\left(\chi^{2}=4.34\right.$; d.f. $\left.=1 ; P<0.05\right)$. No significant differences were found in the incidence of the other two words.

\section{DISCUSSION}

Since the time cigarette smoking was recognized as a serious health hazard, ways to increase people's motivation to abstain from smoking have been sought. Among the factors affecting smokers' motivation to quit, the perception of personal relevance

Table 4. Incidence of words with threatening connotations in the answers of 1-2-pack smokers*

\begin{tabular}{lcccc}
\hline & $\begin{array}{c}\text { Group A: "Moderate" } \\
(\mathrm{N}=24)\end{array}$ & \multicolumn{2}{c}{$\begin{array}{c}\text { Group B: "Heavy" } \\
(\mathrm{N}=14)\end{array}$} \\
& $\mathrm{N}$ & $\%$ & $\mathrm{~N}$ & $\%$ \\
\hline Lung & 13 & 54.2 & 2 & 14.3 \\
Heart & 5 & 20.8 & 3 & 21.4 \\
Cancer & 5 & 20.8 & 2 & 14.3 \\
\hline
\end{tabular}

*Only specific answers (see Table 2) were included. 
of the risk of smoking is certainly one of the most important. If one follows the conceptualization of the Health Belief Model (Rosenstock, 1974), one realizes that motivation to take preventive action requires that smokers not only perceive the severity of the risk - a risk which increases with the amount smoked--but also be aware of their personal vulnerability. It is important therefore to investigate how realistic the smoker's self-identification is as a lighter or heavier smoker, that is, as a smoker who faces a smaller or greater risk.

The results of a questionnaire on smoking and health showed that $60 \%$ of a sample of smokers who smoked between 1 and 2 packages of cigarettes per day considered themselves to be moderate smokers. In our present social climate, which discourages smoking in any amount and emphasizes the serious risk of excessive smoking, the self-categorization of the 1-2-pack smokers as "moderate" appears to be unrealistic. It is our contention that the inappropriate self-labeling of these smokers is part of their mechanisms for reducing cognitive dissonance.

Fewer female than male smokers considered themselves "moderate" smokers. Also, a low percentage of smokers who identified themselves as "moderate" was found in the younger portion of our sample. These differences are not surprising. Women are relative newcomers to the field of smoking. Since-to use an expression familiar in advertising - "they have come a long way" from the time smoking - and especially heavy smoking-was a male prerogative, it is possible that their perception of themselves as heavy smokers is an affirmation of equality with men. For the young smokers, proclaiming themselves heavy smokers may have a certain appeal, being associated with conceptions of toughness and boldness. Sex and age differences in attitudes and beliefs about smoking, however, deserve more attention than is possible to give them in the present study. The small size of the sample limits the feasibility of inter-group comparisons.

In terms of wish to stop smoking, past attempts to quit, intention to join a clinic for treatment, and evaluation of risk for different categories of smokers, no substantial difference between the "moderate" and "heavy" smokers could be detected. The analysis of the answers to the open-ended question "in which way... do you believe that smoking is bad for your health" suggested, however, differences in perception and awareness of the health risk of smoking. The overall impression produced by the answers of the "moderate" smokers is that the majority of respondents were informed, in contact with reality, and not hiding from themselves the heavy risk of continuing to smoke. These respondents cited several ways smoking could affect their health, gave prominence to the severe pathological conditions produced by smoking, and frequently used the word lung in their answers. The other set of answers gives the impression that the respondents had some reluctance to face the consequences, and especially the long-term consequences, of smoking. These smokers reported only one effect of smoking, primarily cited symptoms or disturbances induced by smoking, and seldom used the word lung in their answers.

Strangely, the two types of answers, as outlined above, seem to be at odds with the self-categorization of the smokers. The group of smokers who, on the whole, gave answers characterized by a realistic appreciation of the risk of smoking are the ones who considered themselves "moderate" smokers, a self-identification which does not seem realistic for people who smoke more than one package of cigarettes per day. The reverse could be said for the answers of the smokers who considered themselves "heavy" smokers. The apparent contradiction, however, disappears if one interprets the results in terms of cognitive dissonance. Those smokers who consider themselves "moderate" have, by minimizing the extent of their smoking, reduced their cognitive dissonance. Even if they admit that smoking is bad for their health, they may feel that their risk is relatively moderate. These individuals have therefore less difficulty in facing the knowledge of the multiple ill effects of smoking. On the other hand, smokers who more realistically identify themselves as "heavy" smokers cannot hide from themselves the fact that they are in the higher-risk category. These smokers have therefore to make recourse to other means for reducing their cognitive dissonance. This they do by focusing their attention on 
symptoms, rather than on the pathology of smoking, and by avoiding words which, in the context of smoking, have threatening associations.

In conclusion, within the limitations of a small-size sample, the results of this study suggest that the smokers' self-identification may affect their beliefs and attitudes toward information on the health hazard of smoking. By placing themselves in a lower-risk category, many smokers may lower their perception of personal risk and consequently may feel less motivated to modify their smoking behavior. The importance of verifying how smokers identify themselves is evident not only for its possible clinical applications, but also for the planning of anti-smoking campaigns. If the heavy smokers' tendency to minimize the extent of their smoking suggested by this study can be found to be a general phenomenon, not much could be gained, for instance, by disseminating educational material which illustrates heavy addiction, as seen in recent U.S. television spots. On the contrary, this type of illustration may reinforce many smokers' feelings that they are not "as badly off as that" and may lower their awareness of personal risk.

Acknowledgements - The valuable assistance of Sally Vaughn in the collection and analysis of data is gratefully acknowledged. Helpful comments and suggestions were given by Drs W. Horvath and J. Cross.

\section{REFERENCES}

Bowden, P. The relationship between different evaluations of drinking behavior. Psychological Medicine, 1976, 6, $139-142$.

Doll, R. Smoking and disease: prospects for control. Royal Society of Health, 1977, 4, 167-176.

Eiser, J. R., Sutton, S. R. \& Wober, M. "Consonant" and "dissonant" smokers and the self-attribution of addiction. Addictive Behaviors, 1978, 3, 99-106.

Feather, N. T. Cognitive dissonance, sensitivity, and evaluation. Journal of Abnormal and Social Psychology, $1963,66(2), 157-163$.

Festinger, L. A Theory of Cognitive Dissonance, Evanston, lllinois: Row, Peterson \& Co., 1957.

Pervin, L. A. \& Yatko, R. J. Cigarette smoking and alternative methods of reducing dissonance. Journal of Personality and Social Psychology, 1965, 2(1), 30-36.

Rosenstock, I. M. The health belief model and preventive health behavior. Health Education Monographs, $1974,2,354-386$.

Russell, M. A. H. The smoking habit and its classification. The Practitioner, 1974, 212, 791-800.

Schachter, S. Nicotine regulation in heavy and light smokers. Journal of Experimental Psychology: General. $1977,106(1), 5-12$.

Tagliacozzo, R. Smoking behavior and the avoidance of dissonant information. MHRI Report, December, 1978.

Wynder, E. L. Interrelationship of smoking to other variables and preventive approaches. In M. E. Jarvik et al. (Ed), Research on Smoking Behavior, National Institute on Drug Abuse, Research Monograph 17, 1977, pp. $67-97$. 